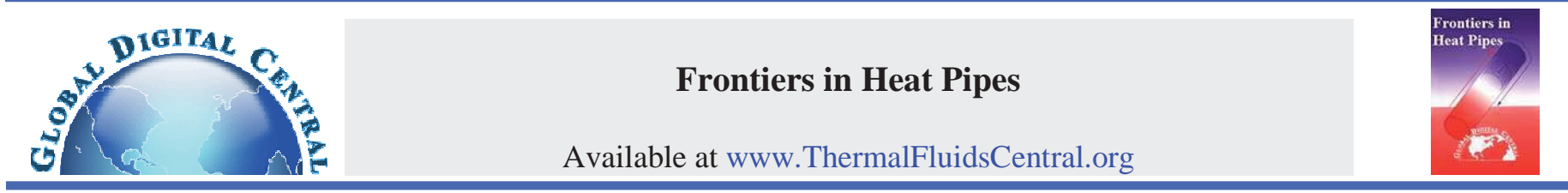

\title{
EFFECT OF WORKING FLUID, FILLING RATIO AND NUMBER OF TURNS ON PULSATING HEAT PIPE THERMAL PERFORMANCE
}

\author{
Rahul S. Borkar ${ }^{a^{*}}$, Pramod R. Pachghare ${ }^{b}$ \\ ${ }^{a}$ Department of Mechanical Engineering, Navsahyadri Group of Institutes Faculty of Engineering, Naigaon-Pune412213, India \\ ${ }^{b}$ Department of Mechanical Engineering, Government College of Engineering, Amravati-444 604, India
}

\begin{abstract}
Pulsating heat pipe's (PHP) are one of the alternatives to conventional heat transfer technologies. First part of this paper, titled: thermohydrodynamic behavior of methanol charged closed loop pulsating heat pipe has given information about thermo-hydrodynamic operational characteristics such as; bubble nucleation and collapse, bubble agglomeration and pumping action, flow regime changes, pressure/temperature perturbations, dynamic instabilities, meta-stable non-equilibrium conditions etc. in the PHP. Present paper, which is an extension of the previous work, it presents some more thermal results to highlight the effect of; thermo-physical properties of working fluid, filling ratio and number of turns on thermal performance of PHP. Three different PHP loop has been made from six, four and two parallel glass tubes (i.e. three turns, two turns and one turn at evaporator section) forming adiabatic section, interconnected alternately by copper $U$ tubes, having internal and external diameter 2 mm and $3.06 \mathrm{~mm}$ respectively. The length of evaporator, condenser and adiabatic section are $42 \mathrm{~mm}, 50 \mathrm{~mm}$ and $170 \mathrm{~mm}$ respectively. The experimentation conducted for different working fluids (water, ethanol, methanol and acetone), different filling ratio’s (30\%FR, 50\%FR and 70\%FR) and different number of turns (one, two and three turns). The motto of present research is to understand the thermal performance in terms of thermal resistance of PHP in details. The result shows that, thermal resistance for all working fluid PHP's rapidly decreases with increasing heating power up to 32W. For low heating power, working fluid (acetone) which has lower boiling temperature is best, but it cannot give the service for higher heating power. Two turn PHP loop with methanol 50\% volumetric filling ratio at more than $32 \mathrm{~W}$ heating power with one directional flow circulation is the optimum operating condition of present research.
\end{abstract}

Keywords: Pulsating heat pipe, phase, passive, flow pattern

\section{INTRODUCTION}

Closed Loop Pulsating Heat Pipe (PHP) is a two-phase passive heat transfer device proposed and patented by Akachi (1990). A PHP is a simple in structure with a small diameter coil partially filled with certain working fluid in it and extended from the heat source to sink. PHP uses the technique of transporting the working fluid by means of differential pressure across liquid slugs and vapor plugs from evaporator to condenser and reverse.

The fluid from the evaporator is pushed towards the condenser in the form of discrete liquid slugs and vapor bubbles. The vapor gets partially condensed at the condenser where it loses its latent heat and then returns to evaporator and completes the cycle. A PHP is being explored for thermal management of electronic devices to remove heat without any electrical power supply and it able to dissipate substantial amount of heat with small temperature drop, simple design and low cost.

The working fluid with the lower latent heat of vaporization exhibits a higher critical heat flux. Mass transfer characteristics are also affected by the local hydrodynamic properties of the flow (Bercic and Pintar, 1997).

Tong et al. (2001) observed that during the startup period, the working fluid oscillate with large amplitude, after this period continuous circulation of the working fluid occurs. The direction of circulation for working fluid is consistent once circulation is obtained but the direction of circulation can be different for same experimental run. Smaller vapor bubbles have larger upward flow velocities and slower downward flow velocity.

Khandekar and Groll (2003) conducted experiments on a PHP made of copper capillary tube of $2 \mathrm{~mm}$ inner diameter for three different working fluids viz. water, ethanol and R-123. The PHP was tested in vertical (bottom heat mode) as well as horizontal orientation and indicated that, a 100\% filled PHP (not working in the pulsating mode but instead as a single-phase buoyancy-induced thermosyphon) is thermally better performing than a partially filled pulsating mode device under certain operating conditions. Higher input heat fluxes result in a transition of slug flow to annular flow at the outlet of the evaporator U-bends. Since the evaporator U-sections experience convective boiling through the thin liquid film rather than nucleate type boiling in slug flow regime.

Khandekar and Groll (2004) studied that, complete stop-over is in the loop occurs more frequently for filling ratio $<50 \%$ coupled with low heat input power. Stop-over phenomenon has also been observed for higher filling ratios. The 'self-sustained' oscillating character is then lost, such a behavior has never been reported for multi-turn PHPs because of alternating periods in which bubble plugs are moving rapidly (activity phase) and 'stopping' (static phase). Kammuang-lue et al. (2008) studied that, the higher latent heat of the working fluid the higher critical heat flux. Yang et al. (2009) pointed out that increasing heat load clearly improves the thermal performance. Meena et al. (2009) concluded that as working fluids change from R123 to ethanol and water the critical heat flux decreased. The latent heat of vaporization affects the critical heat flux. 
Khandekar et al. (2009) observed that the quasi-steady state corresponding to best thermal performance consists of continuous unidirectional flow circulations, while the state corresponding to poor thermal performance is characterized by the intermittent bidirectional flow reversals. Oscillating Taylor bubble flows require immediate attention (Khandekar et al., 2010), unless the nuances of oscillatory confined bubbles in small capillaries is well discerned, the net pressure drop correlations for a PHP cannot be exhaustively constructed.

Dadong and Cui (2010) indicated that the thermal resistance decreases with the increase of the heating power at the same filling ratio. For the pure working fluid PHPs, the thermal resistance is decreases in the sequence of water, ethanol, methanol and acetone. No measurable difference has been recorded between a PHP running with the azeotropic mixture and a PHP running with pure ethanol, in terms of overall thermal resistance Mameli et al. (2011).

Pachghare and Mahalle (2012) conducted experiments on PHP to investigate the effect of binary mixture of working fluids on thermal performance of PHP, made from copper tube with $2 \mathrm{~mm}$ inner diameter and 10 numbers of turns, for different heat inputs with ethanol, methanol, acetone, water and their binary mixture with water as a working fluids at filling ratio $50 \%$. Pure acetone is having lesser thermal resistance than working fluids methanol, ethanol, and water.

No measurable difference has been recorded between the PHP running with pure and binary mixture working fluids, in terms of overall thermal resistance. Working fluid behavior is strongly depends on the thermo-physical properties, but latent heat of vaporization is the main property that strongly affects the thermal performance (Borkar Pachghare, 2012).

\section{EXPERIMENTATION}

\subsection{Experimental set-up}

The experimental set-up of PHP has been developed as shown in Figure 1. The details of copper-glass tube assembly and evaporator tank as shown in Figure 2. The set-up consists of a three different closed loop PHPs, temperature recorder, power supply unit, and water tank cooling system for condenser.

Evaporator sections (Length $42 \mathrm{~mm}$ ) and condenser sections (Length $50 \mathrm{~mm}$ ) are made of copper capillary tube having inner diameter is $2 \mathrm{~mm}$ and the outer diameter is $3.06 \mathrm{~mm}$. The adiabatic section (Length $170 \mathrm{~mm}$ ) made from borosilicate glass tube to understanding flow pattern for different heat inputs. Fluid motion and flow patterns have been captured with a camera (Nikon ${ }^{\circledR}$, COOLPIXP60, 8.1 Megapixel, 5X Zoom) just above the evaporator section.

The heating power is provided by a carefully designed power supply unit. Heating was done by oil bath and cooling by water tank with maintained $30 \mathrm{ml} / \mathrm{min}$ water flow rate through condenser. The power meter measures the AC voltage, the current and the corresponding temperature simultaneously. The filling ratio 50\% was maintained. The heating configuration was bottom heat orientation. For temperature measurements, ungrounded sheathed thermocouples (KType, accuracy $\pm 0.2^{0} \mathrm{C}$ and $\mathrm{D}=0.5 \mathrm{~mm}$ ) were used. All the thermocouples are mounted on the wall of the PHP tubes. Filing of the PHP is only done when the internal vacuum level is at least lower or equal to 0.99 bar.

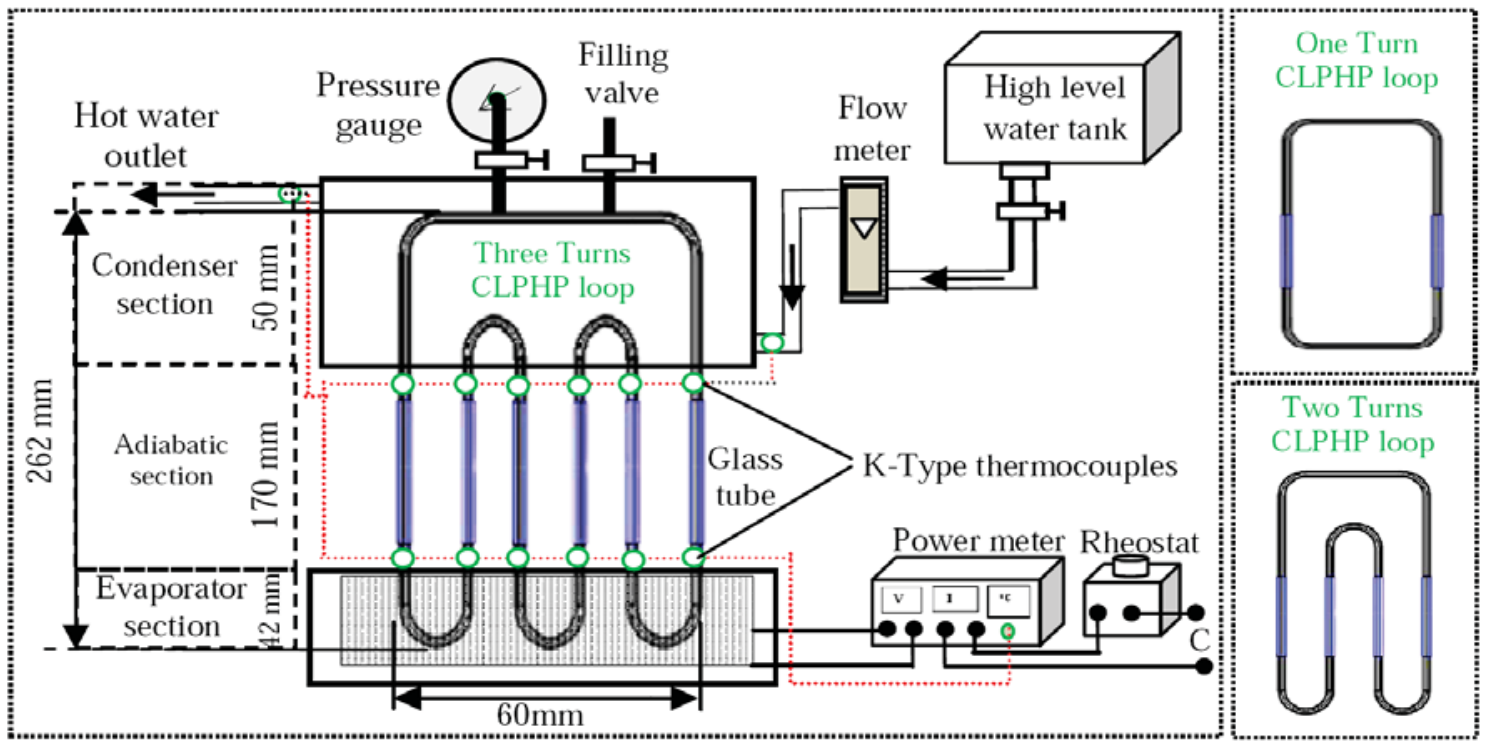

Fig. 1 Schematic of experimental set-up

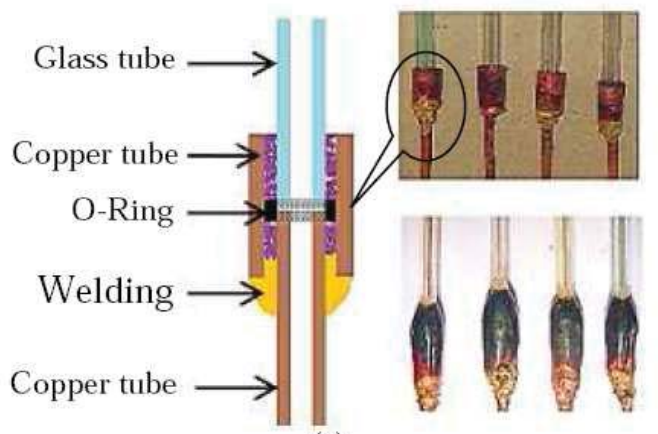

(a)

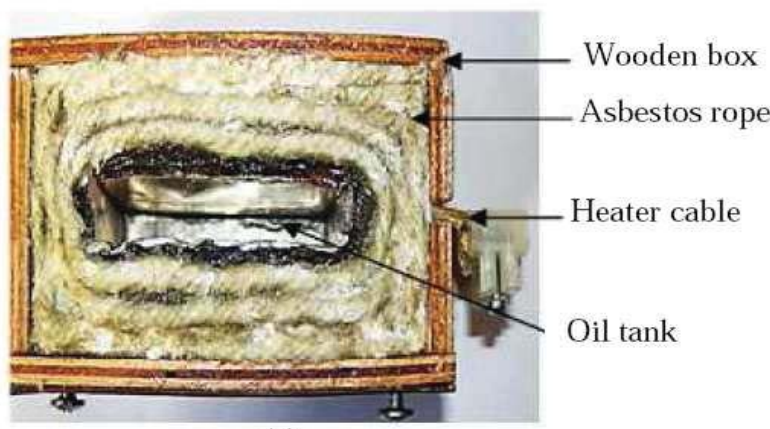

(b)

Fig. 2 Assembly details (a) copper and glass tubes (b) evaporator tank 
Relation of surface tension and bouncy could be explained by the dimensionless formula in Eq. (1):

$$
\mathrm{E} \ddot{0}=\frac{g_{\text {cri }}^{2}\left[\rho_{\text {liq }}-\rho_{\text {vap }}\right]}{\sigma}
$$

When Eö $=4$, the bubble will get seized on both size of wall. At this condition, the terminal velocity becomes zero and the fluid slug flow is formed. The inner diameter of the tube must be small enough such that liquid vapor plugs and slugs exist. Such condition is ensured only if inner diameter of a tube is smaller than a critical diameter. The required diameter calculated by using following Eq. (2).

$$
D_{c r i} \leq 2 \times \sqrt{\frac{\sigma}{g\left[\rho_{\text {liq }}-\rho_{\text {vap }}\right]}}
$$

Selected tube for PHP loop have inner diameter (2 mm), which is less than critical diameter for all selected working fluids. Two smaller copper tubes has been brazed on the main tube of the condenser section in order to connect the vacuum/filling valve and pressure indicator as shown in Figure 1.

The glass tube attached to copper tubes in the condenser section and evaporator section by following procedure:

1. At each end of the U-turns a $5 \mathrm{~mm}$ inner diameter copper tubes are attached by welding (i.e. copper fitting).

2. The $4 \mathrm{~mm}$ outer diameter of glass tubes are inserted in the copper fitting and coupled to the copper tubes by mean of an O-ring.

3. Mixture of m-seal and araldite is fill in the remaining gap between the copper fitting and the glass tube above and below the O-ring, thus ensuring a good seal as shown in Figure 2-a.

The evaporator section was heated by oil bath for uniform heating. A flat flexible heater (450W) has been placed at one side of the evaporator oil tank. Insulation is provided on tank by two asbestos sheet (width: $3 \mathrm{~mm}$ ) and the whole assembly is kept in wooden block, remaining gaff between oil tank and wooden block wall is filled with glass wool for better insulation and asbestos rope is kept on glass wool and fixed by araldite as shown in Figure 2-b.

\subsection{Experimental procedure}

The experimental set-up is used for experimentation and the following procedure is adopted during the present transient experiment:

1. Before filling the working fluid, it is ensured that there were no other impurities exist inside the tubes of PHP.

2. In order to obtain vacuum inside the PHP, a reciprocating vacuum pump is connected to the filling valve. Filing of the PHP is only done when the internal vacuum level is lower than or equals to 0.99 bar.

3. Once the evacuation of the PHP system is complete, the valves are closed. The required amount of working fluid is then filled by opening the one valve as shown in Figure 1. The PHP is filled with the working fluid with a required filling ratio at ambient temperature $\left(25^{0} \mathrm{C} \pm 2^{0} \mathrm{C}\right)$.

4. The cooling water is allowed to the condenser section of PHP from the water bath and the amount of cooling water flow rate $30 \mathrm{ml} / \mathrm{min}$ is maintained during entire experimentation.

5. The required input heat power supply from control panel.

6. The temperature indicator is then switched on to record the temperature.

7. After a quasi-steady state was reached continuous movies were recorded and photographs were taken at specified times by digital camera. At steady state from inlet, outlet temperature and mass flow rate of coolant the heat transfer rate through PHP calculated.
8. Evaporator and condenser temperature recorded at each steady state and again increase heating power by $8 \mathrm{~W}$.

9. Transient experiments are conducted for different heat inputs with different working fluids, number of turns and filling ratios.

\section{RESULTS AND DICUSSIONS}

Three different experiments have been conducted on PHP. Heat input to the evaporator section has been increased with steps of $8 \mathrm{~W}$, starting from $8 \mathrm{~W}$ to $80 \mathrm{~W}$. When, the steady-state has reached for each heat input level then temperature for different points recorded and the overall thermal performance of the PHP has been estimated. Variable and fixed parameters for different experiments are shown in table -1 .

\begin{tabular}{|c|c|c|}
\hline \multicolumn{3}{|c|}{ Experimentation: $1^{\text {st }}$} \\
\hline Filling Ratio & $50 \%$ & \multirow{3}{*}{$\begin{array}{l}\text { Fixed } \\
\text { Parameters }\end{array}$} \\
\hline Turns & 2 & \\
\hline Inclination & Vertical & \\
\hline Working Fluids & $\begin{array}{l}\text { Water, Ethanol, } \\
\text { Methanol and } \\
\text { Acetone }\end{array}$ & $\begin{array}{l}\text { Variable } \\
\text { Parameters }\end{array}$ \\
\hline \multicolumn{3}{|c|}{ Experimentation: $2^{\text {nd }}$} \\
\hline Turns & 1,2 and 3 & $\begin{array}{l}\text { Variable } \\
\text { Parameters }\end{array}$ \\
\hline Filling Ratio & $50 \%$ & \multirow{3}{*}{$\begin{array}{l}\text { Fixed } \\
\text { Parameter }\end{array}$} \\
\hline Inclination & Vertical & \\
\hline Working Fluids & Methanol & \\
\hline \multicolumn{3}{|c|}{ Experimentation: $3^{\text {rd }}$} \\
\hline Filling Ratio & $30 \%, 50 \%$ and $70 \%$ & $\begin{array}{l}\text { Variable } \\
\text { Parameters }\end{array}$ \\
\hline Turns & 1 & \multirow{3}{*}{$\begin{array}{l}\text { Fixed } \\
\text { Parameters }\end{array}$} \\
\hline Inclination & Vertical & \\
\hline Working Fluids & Methanol & \\
\hline
\end{tabular}

Table -1: Input parameters for different experimentation's

In the ideal measurement, the value assigned by the measurement would be the actual value of the physical variable intended to be measured. However, measurement errors bring on an uncertainty in the correctness of the value resulting from the measurement. To give some measure of confidence to the measured value, measurement errors must be identified, and their probable effect on the result estimated. Uncertainty is simply an estimate of a possible value for the error in the reported results of a measurement. The uncertainty in the evaporator temperature and condenser temperature are evaluated about $0.11 \%$ and $0.31 \%$ respectively. The uncertainty for the heat input is 4.46 and the uncertainty for overall thermal resistance is $4.5 \%$.( Kline et al., 1953).

The overall thermal resistance of PHP defined as the ratio of the average temperature difference between the evaporator and condenser to the power input. It can be calculated as:

$\mathrm{R}_{\mathrm{th}}=\frac{\mathrm{T}_{\mathrm{e}}-\mathrm{T}_{\mathrm{c}}}{\mathrm{Q}}$

Where, Q is the net heat input power to the PHP at evaporator by considering thermal loses.

\subsection{Thermo-hydrodynamic behavior of PHP}

In the first part of this paper, Borkar and Pachghare (2014) conclude that, the thermal performance of device increases with increasing heat input. With increasing heat input, the evaporator temperature rises, resulting in a greater density gradient in the tubes, simultaneously the liquid viscosity also drops, that diminishing the wall friction and evaporation rate of working fluid inside the loop. 


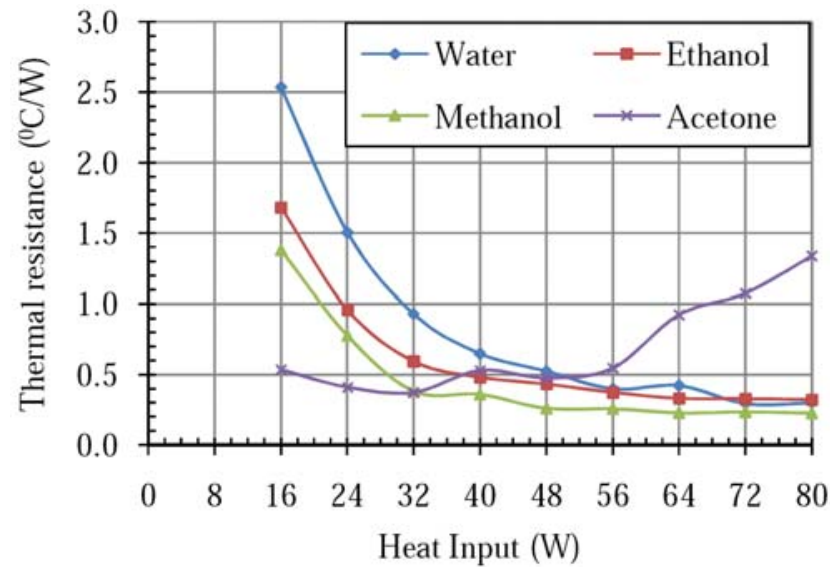

Fig. 3 Thermal resistance of PHP for different working fluids (Experiment- $1^{\text {st }}$ )

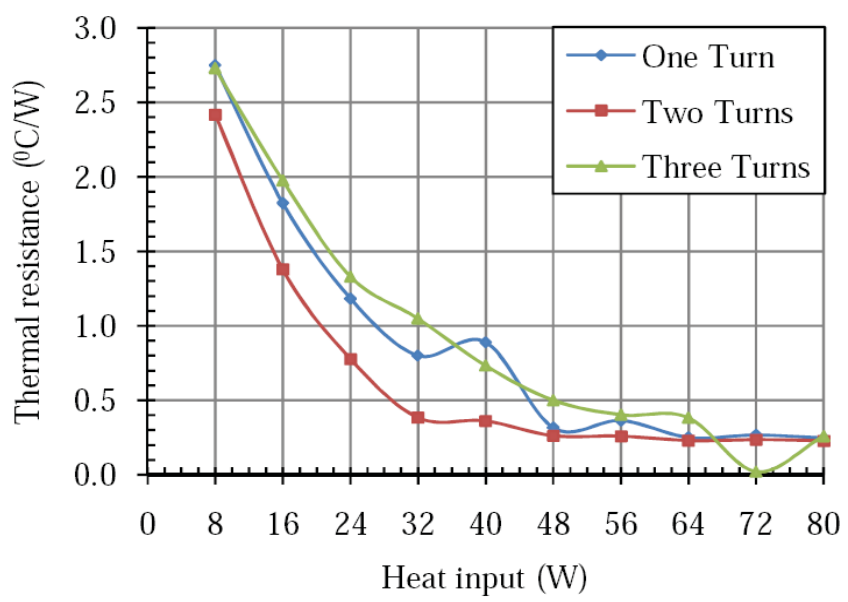

Fig. 5 Thermal resistance of PHP for different turns (Experiment- $2^{\text {nd }}$ )

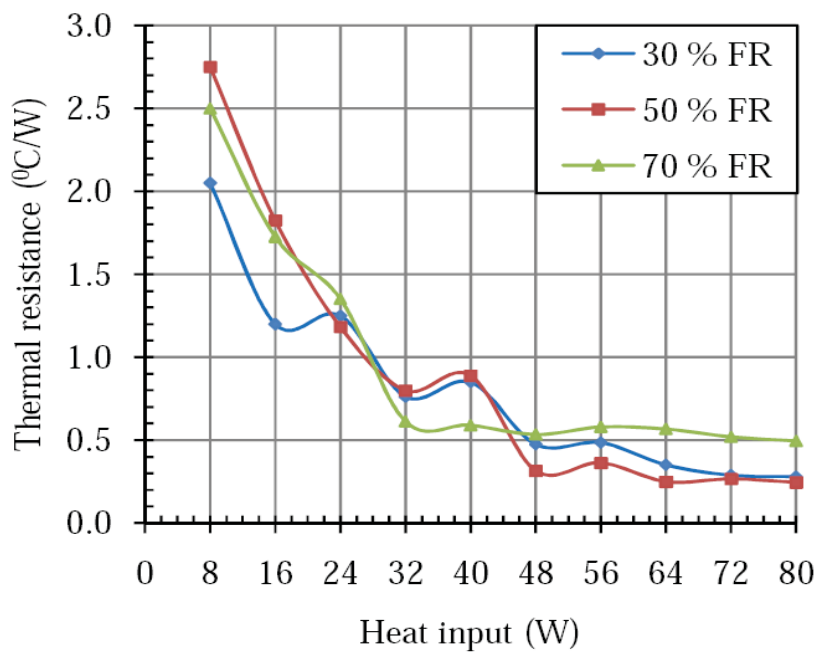

Fig. 7 Thermal resistance of PHP for different filling ratio (FR) (Experiment- $3^{\text {rd }}$ )

Nucleate boiling and convective boiling at liquid-slugs and vaporplugs respectively, rate of boiling increase with heating power. Input heat at evaporation section cause the temperature difference between evaporator and condenser section which is responsible for internal pressure fluctuation (i.e. Driving potential of PHP increase with respect to increasing heat input) therefore thermal resistance decrease with

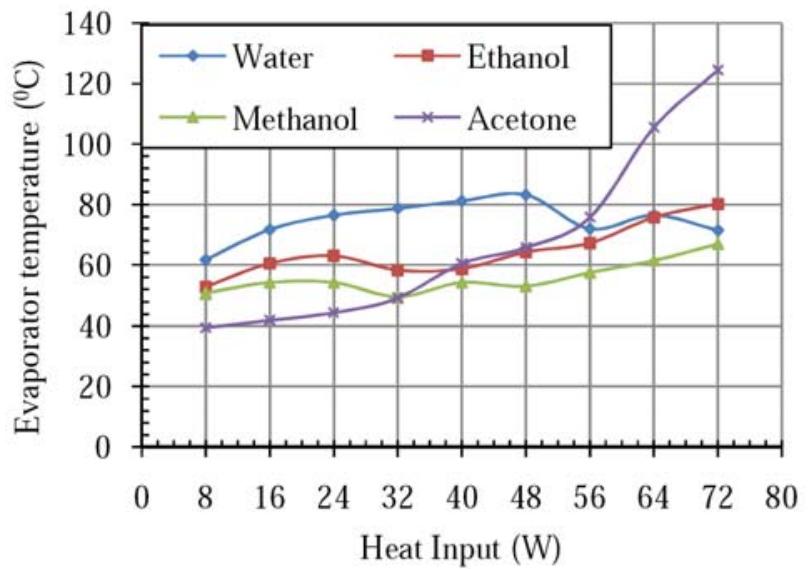

Fig. 4 Evaporator temperature of PHP for different working fluids (Experiment- $1^{\text {st }}$ )

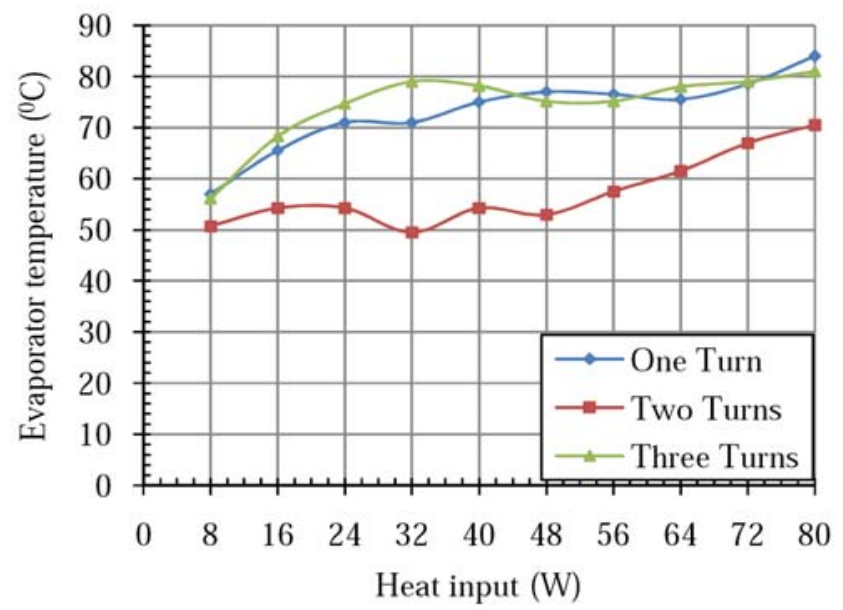

Fig. 6 Evaporator temperature of PHP for different turns (Experiment-2 $\left.{ }^{\text {nd }}\right)$

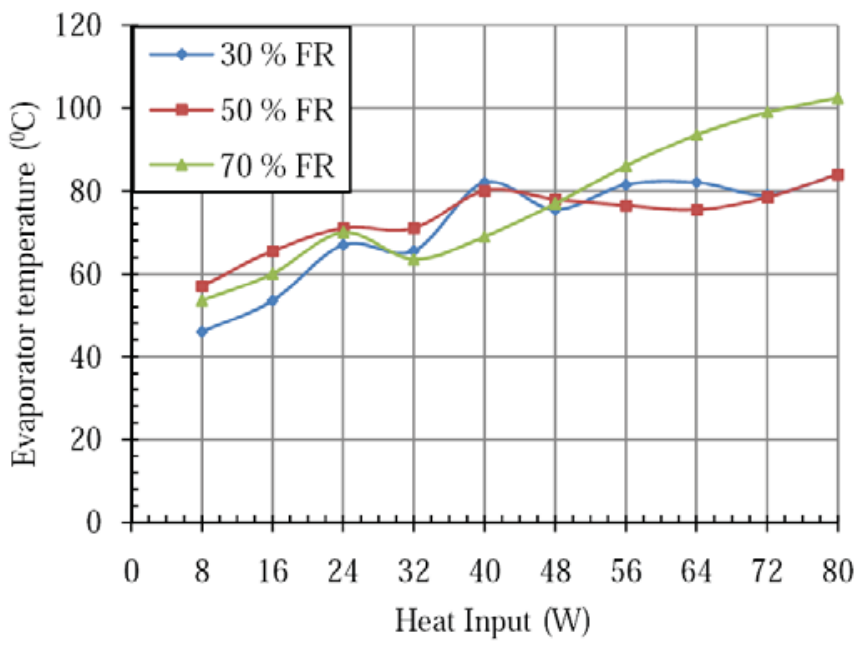

Fig. 8 Evaporator temperature of PHP for different filling ratio (FR) (Experiment- $3^{\text {rd }}$ )

increase in heat input. During starting period, the rate of fluctuation of liquid-slug was slow and increased with increasing heating power. Maximum heat transferred at one directional flow circulation mode, than only pulsation mode. The thermal performance of PHP is independent on the direction of flow circulation (clock wise or anti clock wise). 


\subsection{Effect of working fluid properties}

Experimentation-1 $\mathbf{1}^{\text {st}}$ : To understand effect of thermo-physical properties of working fluid (Table-2) on thermal performance of PHP, four different working fluids (i.e. water, ethanol, methanol and acetone are selected. Figure $3 \& 4$ shows the results from $1^{\text {st }}$ experiment.

Latent heat: A low latent heat will cause the liquid to evaporate more quickly at a given temperature and a higher vapor pressure; the liquid slug oscillating velocities has increased and the thermal performance of the PHP also improved up to $32 \mathrm{~W}$, on the other hand the dry-out phenomenon occurred after 64W heat input levels.

Specific heat: A high specific heat will increase the amount of sensible heat transferred. Because in most of the cases a great percentage of the total heat transfer in a PHP is due to sensible heat, a fluid (water) with a high specific heat is desirable for high heating power (80W), dry out condition has not observed.

Effect of boiling point: Figure 4 shows that, an evaporator wall temperature is higher for water PHP and lower in the case of acetone PHP. It is also observed that the system takes more time to reach the steady state in case of water compared to acetone. Acetone PHP showed the low evaporator wall temperature up to input heat power 32 $\mathrm{W}$. After $32 \mathrm{~W}$ input heating power the evaporator temperature of acetone PHP is increasing gradually up to input heat power $56 \mathrm{~W}$, and then rapidly increased for further input heat power. Because, acetone has low boiling point as well as low specific heat, therefore evaporation rate is very high for higher heating power and almost all fluid at evaporator tubes is vaporized that's why the temperature increased at high input level, resulting evaporator-condenser temperature difference increased rapidly than other working fluids. Working fluids which have high boiling temperature, for that fluid more heat input to start evaporation.

Effect of surface tension: The surface tension provides additional capillary resistance and affected on the internal pressure fluctuation. Higher surface tensions will increase the maximum allowable diameter and also the pressure drop in the tube. Larger diameter will allow improved performance, but an increased pressure drop will require greater bubble pumping and thus a higher heat input to maintain pulsating flow. The fluid which has low surface tension gives the best thermal performance but it will increase the maximum allowable diameter.

Effect of Viscosity: As increasing heat input, the evaporator temperature also rises, resulting liquid viscosity drops. A low dynamic viscosity will reduce shear stress along the wall and will consequently reduce pressure drop in the tube. This will reduce the heat input required to maintain a pulsating flow. All properties are strongly affected on thermal performance.

Effect of different working fluids: From the above description it is concluded that, the fluid which has lower boiling point is more suitable for lower heating power because of sufficient evaporation rate but the situation is reversed in case of high heating power. From figure 3 it is found that, acetone PHP given best performance at low heating power up to $32 \mathrm{~W}$ then after $32 \mathrm{~W}$ to $80 \mathrm{~W}$ other fluids showing better thermal performance. So by taking optimum performance in to the account; working fluid methanol has selected for 2nd experimentation.

\subsection{Effect of number of turns}

Experimentation-2 ${ }^{\text {nd: }}$ : The number of turns in the PHP may affect thermal performance making negligible the effect of gravity. By increasing the number of turns, there are more distinct locations for heat to be applied and more local pressure drops. The higher level of local perturbations helps to avoid vapor phase recoiling in the evaporator and liquid merging in the condenser. The uneven distribution of liquid slugs and vapor plugs inside heating and cooling sections is necessary to create differences in pressure at each turn which drives the pulsating flow. Figure $5 \& 6$ shows the results from $2^{\text {nd }}$ experiment. From Figure 5 , it has been found that, the PHP with two turns gives the best performance than one and three turns PHP (Khandekar et al., 2011).

\subsection{Effect of filling ratio}

Experimentation- $3^{\text {rd }}$ : Filling ratio (FR) of a PHP is defined as the ratio of working fluid volume actually present in the device to that of the total volume of the device (say at room temperature). Thus, a given PHP has two operational extremities with respect to the filling ratio, an empty device without any working fluid i.e. $\mathrm{FR}=0$ and a fully filled device i.e. $\mathrm{FR}=1$. It is obvious that at $\mathrm{FR}=0$, the empty PHP tubes constitute inefficient conduction fins and obviously have a very high thermal resistance. A fully filled PHP $(F R=1)$ is identical in operation to a single-phase thermosyphon. There exist no bubbles in the tube and so no "pulsating" effect is present. Substantial sensible heat transfer can still take place due to liquid circulation in the tubes by thermally induced buoyancy (Khandekar et. al., 2008).

Figure $7 \& 8$ shows the results from $3^{\text {rd }}$ experiment. From Figure 7; it found that, optimum performance obtained at $50 \%$ FR. For lower heating power 30\%FR gives the best performance, but at higher heating power, there is very little liquid to form enough distinct slugs and there is a tendency towards dry-out of the evaporator.

\section{CONCLUSIONS}

From the investigation of the PHP at different heat input, fluids, filling ratio and number of turns, the following findings are obtained.

1. The fluid which has lower boiling point is more suitable for lower heating power because of sufficient evaporation rate but the situation is reversed in case of high heating power.

2. Acetone is best for low heating power up to $32 \mathrm{~W}$, then after heating power $32 \mathrm{~W}$ to $80 \mathrm{~W}$, other fluids are showing better thermal performance.

3. Thermal performance of PHP is depends on behavior of working fluid with respect to heat input. The methanol PHP is more suitable for heat input between $40 \mathrm{~W}$ to $80 \mathrm{~W}$.

4. Optimum performance obtained at 50\% FR. For lower heating power 30\%FR gives the best performance, but at higher heating power, there is very little liquid to form enough distinct slugs and there is a tendency towards dry-out of the evaporator.

5. Two turns PHP gives best performance, because of better level of perturbations thereby diminishing the probability of phase recoiling and consequent complete stop-over of the fluid motion.

\section{ACKNOWLEDGEMENTS}

Special thanks to my Father and Brother for motivation and economical support to present research.

\section{NOMENCLATURE}

D Diameter (m)

EÖ EÖtvÖs number

$\mathrm{R}_{\mathrm{th}} \quad$ Thermal resistance $\left({ }^{0} \mathrm{C} / \mathrm{W}\right)$

$\mathrm{T} \quad$ Average temperature $\left({ }^{0} \mathrm{C}\right)$

$\mathrm{Tb} \quad$ Boiling temperature $\left({ }^{0} \mathrm{C}\right)$

hfg latent heat $(\mathrm{kJ} / \mathrm{kg})$

Cp Specific heat $(\mathrm{KJ} / \mathrm{Kg}-\mathrm{K})$

\section{Greek Symbols}

$\sigma \quad$ Surface tension $(\mathrm{N} / \mathrm{m})$

$\rho \quad$ Density $\left(\mathrm{Kg} / \mathrm{m}^{3}\right)$

g Acceleration due to gravity $\left(\mathrm{m} / \mathrm{s}^{2}\right)$

$\mu \quad$ Dynamic visccosity (Ns/m²)

g Acceleration due to gravity $\left(\mathrm{m} / \mathrm{s}^{2}\right)$

\section{Subscripts}

e evaporator

c condenser 
Table-2: Thermo-physical properties of different working fluids (Faghri, 1995)

\begin{tabular}{|c|c|c|c|c|c|c|c|c|c|}
\hline \multirow{2}{*}{$\begin{array}{l}\text { Working } \\
\text { Fluid }\end{array}$} & \multirow{2}{*}{$\begin{array}{c}\mathrm{Tb} \\
\left({ }^{\circ} \mathrm{C}\right)\end{array}$} & \multirow{2}{*}{$\begin{array}{c}\text { hfg } \\
(\mathrm{kJ} / \mathrm{kg})\end{array}$} & \multicolumn{2}{|c|}{$\rho(\mathrm{Kg} / \mathrm{m} 3)$} & \multicolumn{2}{|c|}{$\mu(10-7 \mathrm{Ns} / \mathrm{m} 2)$} & \multirow{2}{*}{$\begin{array}{c}\sigma \\
(10-3 \\
\mathrm{N} / \mathrm{m}) \\
\end{array}$} & \multicolumn{2}{|c|}{ Cp (KJ/Kg-K) } \\
\hline & & & liq & Vap & Liq & Vap & & liq & Vap \\
\hline Water & 100 & 2251.20 & 958.7 & 0.597 & 2790.0 & 121.00 & 58.91 & 4.22 & 2.034 \\
\hline Ethanol & 78.3 & 962.45 & 758.1 & 1.372 & 4452.6 & 102.39 & 17.46 & 2.73 & 1.604 \\
\hline Methanol & 64.7 & 1119.59 & 750.8 & 0.566 & 3291.4 & 109.64 & 18.87 & 2.52 & 1.601 \\
\hline Acetone & 56.2 & 520.56 & 748.5 & 2.123 & 2340.6 & 89.25 & 19.09 & 2.28 & 1.385 \\
\hline
\end{tabular}

$\begin{array}{ll}\text { liq } & \text { liquid } \\ \text { vap } & \text { vapor } \\ \text { cri } & \text { critical }\end{array}$

\section{REFERENCES}

Akachi, H., 1990, “Structure of a Heat Pipe,” U.S. Patent 4, 921, 041.

Faghri, A., 1995. "Heat Pipe Science and Technology," Taylor and Francis, ISBN: 1-56032-383-3, p. 803-855.

Berčič, G., and Pintar, A., 1997, “The Role of Gas Bubbles and Liquid Slug Lengths on Mass Transport in the Taylor Flow through Capillaries,” Chemical Engineering Science, 52, 3709-3719.

Tong, B., Wong, T., and Ooi, K., 2001, “Closed Loop Pulsating Heat Pipe,” Applied Thermal Engineering, ISSN 1359-4311, Vol. 21/18, pp. 1845-1862.

http://dx.doi.org/10.1016/S1359-4311(01)00063-1

Khandekar, S. and Groll, M., 2003, "On the Definition of Pulsating Heat Pipe,” Proc. 5th Minsk International Seminar (Heat Pipes, Heat Pumps and Refrigerators), Minsk, Belarus.

Khandekar, S., Dollinger N. and Groll M., 2003, "Understanding Operational Regimes of Closed Loop Pulsating Heat Pipes: An Experimental Study," Applied Thermal Engineering, 23, 707-719. http://dx.doi.org/10.1016/S1359-4311(02)00237-5

Khandekar, S., and Groll, M., 2004, "An Insight Into ThermoHydraulic Coupling in Pulsating Heat Pipes,” International Journal of Thermal Sciences, 43(1), 13-20.

http://dx.doi.org/10.1016/S1290-0729(03)00100-5

Kammuang-lue, N., Charoensawan, P., Ritthidech, S., Booddachan, K. and Terdtoon, P., 2008, "Effects of Working Fluids on Heat Transfer Characteristics of a Closed-Loop Pulsating Heat Pipe at Critical State," International Heat Pipe Conference.

Yang, H., Khandekar, S. and Groll, M., 2008, "Operational Limit of Closed Loop Pulsating Heat Pipes”, Applied Thermal Engineering, 28, 49-59

Khandekar, S., Gautam, A. and Sharma, P., 2009, "Multiple QuasiSteady States in a Closed Loop Pulsating Heat Pipe,” International Journal of Thermal Sciences, 48(3), 535-546.

http://dx.doi.org/10.1016/j.ijthermalsci.2008.04.004
Meena, P., Rittidech, S. and Tammasaeng, P., 2009, "Effect of Evaporator Section Lengths and Working Fluids on Operational Limit of Closed Loop Oscillating Heat Pipes with Check Valves (CLOHP/CV),” American Journal of Applied Sciences, 6 (1), 133-136. http://dx.doi.org/10.3844/ajassp.2009.133.136

Yang, H., Khandekar, S. and Groll, M., 2009, "Performance Characteristics of Pulsating Heat Pipes as Integral Thermal Spreaders," International Journal of Thermal Sciences, 48, 815-824. http://dx.doi.org/10.1016/j.ijthermalsci.2008.05.017

Wang, D. and Cui, X., 2010, "Experiment Research on Pulsating Heat Pipe With Different Mixtures Working Fluids,” The $21^{\text {st }}$ International Symposium on Transport Phenomena, Kaohsiung City, Taiwan.

Khandekar, S., Panigrahi, P., Lefèvre, and Bonjour, J., 2010, "Local Hydrodynamics Of Flow In A Pulsating Heat Pipe: A Review," Frontiers in Heat Pipes, 1, 023003.

http://dx.doi.org/10.5098/fhp.v1.2.3003

Mameli, M., Khandekar, S. and Marango, M., 2011, “An Exploratory Study of a Pulsating Heat Pipe Operated with a Two Component Fluid Mixture," Proceedings of the 21st National and 10th ISHMT-ASME Heat and Mass Transfer conference, IIT Madras, India.

Narasimha, K., Sridhara, S., Rajagopal, M. and Seetharamu, K., 2012, "Influenc e of Heat Input, Working Fluid and Evacuation Level on the Performance of Pulsating Heat Pipe," Journal of Applied Fluid Mechanics, Vol. 5/2, pp. 33-42.

Pachghare, P. and Mahalle M., 2012, "Thermal Performance of Closed Loop Pulsating Heat Pipe Using Pure and Binary Working Fluids," Frontiers in Heat Pipes (FHP), 3,033002. http://dx.doi.org/10.5098/fhp.v3.3.3002

Borkar, R. and Pachghare, P., 2014, "Thermo-Hydrodynamic Behavior of Methanol Charged Closed Loop Pulsating Heat Pipe," Frontiers in Heat Pipes (FHP), ISSN: 2155-658X, http://dx.doi.org/10.5098/fhp.5.4

Borkar, R. And Pachghare, P., 2012, State of The Art on Closed Loop Pulsating Heat Pipe," International Journal of Emerging Technology \& Advanced Engineering, Vol. 2/10, pp. 202-207. http://www.ijetae.com/files/Volume2Issue10/IJETAE 1012 36.pdf

Kline, S., and Mcclintock, F., 1953, “The Descriptions of Uncertainties in Single Sample Experiments”, Mechanical Engineering, 75, 3-8 